\title{
Normal-tension glaucoma: Pathogenesis and genetics (Review)
}

\author{
ALEXANDRA TRIVLI $^{1,2}$, IOANNIS KOLIARAKIS ${ }^{3}$, CHRYSSA TERZIDOU $^{1}$, \\ GEORGE N. GOULIELMOS ${ }^{2}$, CHARALAMBOS S. SIGANOS ${ }^{4}$, DEMETRIOS A. SPANDIDOS ${ }^{5}$, \\ GEORGIOS DALIANIS $^{1}$ and EFSTATHIOS T. DETORAKIS ${ }^{4}$
}

\author{
${ }^{1}$ Department of Ophthalmology, Konstantopouleio-Patission General Hospital, 14233 Athens; \\ ${ }^{2}$ Section of Molecular Pathology and Human Genetics, Department of Internal Medicine, School of Medicine, \\ University of Crete, 71003 Heraklion; ${ }^{3}$ Laboratory of Anatomy-Histology-Embryology, Medical School, \\ University of Crete; ${ }^{4}$ Department of Ophthalmology, University Hospital of Heraklion, 71110 Heraklion; \\ ${ }^{5}$ Laboratory of Clinical Virology, Medical School, University of Crete, 71003 Heraklion, Greece
}

Received September 28, 2018; Accepted November 21, 2018

DOI: $10.3892 / \mathrm{etm} .2018 .7011$

\begin{abstract}
Normal-tension glaucoma (NTG) is a multifactorial optic neuropathy which, similar to open-angle glaucomas, is characterized by progressive retinal ganglion cell death and glaucomatous visual field loss. The major distinction of NTG from open-angle glaucomas is that the intraocular pressure (IOP) does not exceed the normal range. Missing the major risk factor and target of therapy, the elevated IOP, NTG poses a clinical challenge. Several insightful reviews have been published on the pathophysiology of NTG describing the possible underlying mechanisms. The current literature available also suggests that a significant percentage of patients with NTG (as high as 21\%) have a family history of glaucoma, indicating a genetic predisposition to the disease. These facts strengthen the indication that NTG remains an enigmatic process. The aim of this review was to summarize the vascular, mechanical and genetic components considered to be responsible for NTG development and to discuss the mechanisms through which they are involved in the pathogenesis of NTG.
\end{abstract}

\section{Contents}

1. Introduction

2. Vascular factors and ocular blood flow

3. Systemic hypotension

4. Vascular dysregulation

5. Mechanical factors

6. Obstructive sleep apnea/hypopnea syndrome

Correspondence to: Dr Alexandra Trivli, Department of Ophthalmology, Konstantopouleio-Patission General Hospital, Agias Olgas 3-5, Nea Ionia, 14233 Athens, Greece

E-mail: alextrivli@yahoo.com

Key words: glaucoma, normal tension, intraocular pressure, pathogenesis, genetics
7. The neurovascular hypothesis of RGC damage in NTG

8. Genetic associations in NTG

9. Conclusions

\section{Introduction}

Normal-tension glaucoma (NTG) is a type of progressive glaucomatous optic neuropathy (GON). Its main difference to primary open-angle glaucoma (POAG) is that NTG presents with normal intraocular pressure (IOP) (1). The epidemiology of NTG varies, being more prevalent among Asian populations, including Japanese and Korean populations, than among Caucasians. NTG is also considered a 'middle-age' disease with the mean age of patients being in the 6th decade of life. Of note, although IOP is measured within a normal range in NTG, optic disc excavation and visual field (VF) defects are detected (2). This suggests an IOP-independent multifactorial background of NTG etiology. The main factors contributing to NTG-related GON can be distinguished into two main categories, namely vascular and mechanical. These factors can lead to retinal ganglion cell (RGC) loss and axonal damage via several pathways (3). In addition, various genes have been found to be involved in NTG, thus suggesting a genetic predisposition for NTG development (4).

The aim of this review was to summarize and analyze the various pathogenetic factors which contribute to the development of NTG-related GON and to present the recent research findings on the genetics of NTG.

\section{Vascular factors and ocular blood flow}

The keystone of the vascular pathogenesis of GON in NTG seems to be a disruption in ocular blood flow (OBF) (5). Although the measurement of OBF remains challenging, with a great variety of available methods and no gold standard method available, studies on patients with glaucoma have indicated a reduction in OBF in ocular tissues (optic nerve, retina and choroid), being more prominent in cases of progressive NTG than in POAG $(5,6)$. 
The reduction in OBF is a multifactorial phenomenon. The role of ocular perfusion pressure (OPP) is known, which is equal to arterial blood pressure (BP) minus IOP, with IOP being equal to retinal venous pressure (RVP) (7). Since IOP is within a normal range in NTG, alterations in BP or RVP can influence OPP. Low OPP, particularly if fluctuating, contributes to the progression of GON (8). Indeed, low systemic blood pressure, particularly during the night, reduces OBF via a reduction in OPP, thus being a major risk factor of NTG progression. Additionally, RVP is increased in patients with glaucoma, resulting also in a lower OPP $(9,10)$. These facts indicate a component related to OPP reduction. As a result, structural damage and low OPP constitute a secondary element of $\mathrm{OBF}$ reduction.

However, a primary component may be involved. Nailfold capillaries also demonstrate a reduction in blood flow, which cannot be connected to glaucomatous damage or IOP. Moreover, a low BP does not enhance GON progression in all cases $(11,12)$. OBF and OPP demonstrate a complex interaction in combination with local flow resistance, with a reduction in resistivity as a regulatory reaction to OPP reduction (5). There is evidence to suggest that in subjects with low $\mathrm{BP}$, a reduction in OPP reduces OBF due to altered autoregulation and defective adaptation (13). OBF reduction in retrobulbar arteries with a distortion of vascular properties, concerning resistance and pulsatility, was recently reported in patients with NTG (14). In addition, $\mathrm{OBF}$ reduction often precedes $\mathrm{GON}$, being a predictor of its progression (15). All these observations have led to the term 'vascular dysregulation' which, in general, describes the lack of maintaining an adequate tissue blood supply, despite alterations in perfusion pressure, embracing irregular systemic or local vasospastic/vasodilating phenomena (5). Vascular dysregulation is considered to be the key primary component of GON pathogenesis in patients with NTG $(12,16)$.

Despite this evidence regarding OBF reduction and GON, OBF reduction in animal models through the administration of endothelin-1 (ET-1), and in patients with multiple sclerosis, has led to only mild optic nerve head (ONH) atrophy and minor excavation $(17,18)$. Thus, it has been proposed that an OBF fluctuation initiates and promotes glaucomatous damage more effectively than baseline OBF, a fact that has been proven (5). OBF instability may be due to high IOP or low BP fluctuation exceeding normal autoregulation, or normal IOP and/or BP fluctuation in the case of altered autoregulation (19). IOP fluctuations are discussed below as a part of mechanical factors in NTG. As regards vascular factors in the case of normal autoregulation, systemic hypotension, particularly nocturnal drops, is responsible for low BP, resulting in an OPP deficit. On the other hand, improper autoregulation implies vascular dysregulation $(10,16)$.

Hence, below, we analyze systemic hypotension with reference to nocturnal drops, and vascular dysregulation, as the major vascular factors of NTG-related GON.

\section{Systemic hypotension}

BP plays a crucial role in NTG. Various studies have indicated systemic hypotension as a common risk factor in patients with NTG with ONH excavation, VF progression, and optic disc hemorrhage $(10,20)$. Notably, Orgul et al reported that the majority of patients with NTG with systemic hypotension also present vasospasm (65\%) (21), indicating an association between low BP and vasospastic disorders, possibly reflecting the additional role of vascular dysregulation $(21,22)$. As previously mentioned, hypotension through OPP reduction creates OBF reduction/fluctuation, particularly when low BP exceeds the capacity of vascular autoregulation, resulting in perfusion deficits and ischemic injuries in optic nerve fibers (10).

These alterations are more prominent in sustained nocturnal BP drops, which are more frequent among NTG cases, almost always being observed in patients with NTG with vasospasm $(10,23)$. A meta-analysis of the correlation between GON and the circadian rhythm of BP, including NTG cases, reported that nocturnal BP drops $>10 \%$ of diurnal BP were a risk factor for $\mathrm{VF}$ defect progression (24). A prospective study was conducted including 85 patients with NTG, and BP was monitored over a 48-h period in 30-min intervals and during follow-up at 6 and 12 months. VF defect progression was observed in $29 \%$ of patients, with a significant predictor of it being sustained nocturnal BP drops $10 \mathrm{mmHg}$ lower compared to diurnal BP (23). Consequently, systemic hypotension, particularly nocturnal BP drops, may be an important risk factor for GON and VF defect progression in NTG, although these findings are still under debate (25).

\section{Vascular dysregulation}

It has been suggested that vascular dysregulation is a primary step initiating glaucomatous damage in NTG via OBF instability, affecting optic nerve and retina by the enhancement of ischemic damage, as well as by promoting the apoptosis of RGCs and their axons (19). The main cause is a systemic form of vascular dysregulation, accompanied by symptoms and signs, thus constituting a 'vascular dysregulation syndrome'. Considering its primary nature in NTG pathogenesis, the term primary vascular dysregulation syndrome or Flammer syndrome (FS) is used $(26,27)$. Other components of vascular dysregulation include migraines, systemic vascular diseases and endothelial dysfunction $(28,29)$. All of these are considered risk factors for GON in NTG cases (4).

Primary vascular dysregulation or FS. Josef Flammer, who first reported this condition, described it as a combination of signs and symptoms together with primary vascular dysregulation, occurring idiopathically in individuals with no vascular disease and resulting in transiently impaired adaptation of blood flow to tissue needs $(12,35)$.

FS is more prevalent among females, Asians, slender subjects and academics, with the initial symptoms becoming evident during puberty $(26,27)$. Although there is no gold standard diagnostic method, diverse signs and symptoms are indicative of FS. Subjects with FS usually have cold hands or/and feet, a reduced feeling of thirst, low BP with pronounced nocturnal drops, an enhanced drug sensitivity, are more susceptive to migraines, and they often have a prolonged sleep onset time (11,30-33).

As regards circulation, subjects with FS display an inborn tendency towards an altered response to various stimuli, such as cold or stress (34). The most overt pathological reactions are irregular vasoconstrictions (vasospasms) (35); hence, FS was 
firstly named 'vasospastic syndrome' (36). In these subjects, the peripheral vessels, particularly in their skin and extremities are constricted, in order to decrease heat loss. In addition, the vascular properties of peripheral circulation in patients with FS (e.g., in nailfold capillaries) are associated with their ocular vessels and $\mathrm{OBF}(34,35)$.

Although the majority of subjects with FS are healthy, they generally demonstrate several ocular signs (26). Their retinal vessels present less flexibility, due to high pulse wave conduction, and higher spatial variability (37). They also exhibit larger choroidal vasoconstriction as a response to a hand-grip test (38). Subjects with FS also have altered responses to BP and IOP due to vessel dysregulation, resulting in an instability of OPP and OBF $(8,27)$. FS is often observed in patients with NTG with progressive GON, contributing to its prevalence and pathogenesis, being a crucial risk factor $(26,27,35)$. FS in NTG is associated with an increased RVP and blood flow resistance in retrobulbar vessels, diffuse VF defects and splinter optic disc hemorrhages, possibly being the main cause of the latter $(26,39)$. Moreover, patients with FS with glaucoma tend to have low diurnal BP, patients with nocturnal drops present similar retrobulbar dynamics with patients with NTG with FS, and NTG cases with systemic hypotension and/or nocturnal drops are largely accompanied by vasospasm $(21,31)$. These facts indicate a possible interrelation between FS and systemic hypotension in NTG.

Therefore, FS leads to GON in patients with NTG mainly due to low BP, increased RVP and improper autoregulation, acting either combined or independently, resulting in $\mathrm{OBF}$ instability (31).

Migraines. A number of studies have suggested an association between migraines and NTG, with migraines being a risk factor for NTG progression $(4,20,40)$. Migraines have been described as a vasospastic disorder, frequently observed in females and particularly in patients with NTG in contrast to those with POAG or control subjects (28). Corbett et al, using various neurological investigations including imaging techniques (CT and ECG) in NTG cases, with $44 \%$ of them having a positive migraine history, revealed that ischemia related to migraine possibly conduces to NTG pathogenesis (40). The 'Low-Pressure Glaucoma Treatment Study" reported migraines as a predicting factor of optic disc hemorrhage in NTG cases (20).

All of the above suggest a common vascular basis of migraines and NTG. Migraines are related to temporary vasospasm, leading to the disruption of autoregulation in cerebral blood flow. Moreover, rapid VF impairment in NTG cases with silent cerebral infarct signifies an additional role of cerebral ischemic damage in GON progression. Impotent vascular autoregulation in subjects with GON can result in various ischemic phenomena, including microinfarctions in ONH and optic disc hemorrhage $(19,41)$. Thus, migraines may be an important indicator of microvascular dysregulation related to NTG (20).

Systemic vascular diseases. Various autoimmune and inflammatory vascular diseases, such as multiple sclerosis, rheumatoid arthritis, lupus erythematosus, giant cell arteritis, antiphospholipid syndrome, Berger's disease and pre-eclampsia, among others, have been linked to vascular dysregulation as a secondary effect of these conditions $(19,22)$. However, it has been suggested that these diseases have a minor impact on autoregulation, hence leading to OBF reduction via increased levels of ET-1 in circulation (26). In addition, a common characteristic of these conditions is the presence of vasospasm which, although transiently occurs, it is well known to be involved in ONH damage in NTG $(22,35)$.

On the whole, considering these vascular diseases, vasospasm and increased plasma ET-1 levels seem to be responsible for OBF dysregulation in NTG.

Endothelial dysfunction. Microcirculation, including retrobulbar microvessels, is mainly regulated through secretion of vasoregulatory factors from endothelial cells, namely nitric oxide (NO) and ET-1, affecting the vascular smooth muscle tone (42). Consequently, an impairment of these factors, or endothelial dysfunction, alters vascular regulation. NO primarily induces vasodilation. Oxidative stress is the major mechanism which impairs NO signaling. NO has also been reported to be involved in ocular autoregulation, presenting an endothelial and neuronal protective role against pathologic alterations in glaucoma (43).

By contrast, ET-1 significantly promotes vasoconstriction interacting with its receptors $\mathrm{ET}_{\mathrm{A}}$ and $\mathrm{ET}_{\mathrm{B}}$. A number of studies have indicated an association between plasma ET-1 levels and NTG pathogenesis (44-47). Increased plasma ET-1 levels have been described in NTG cases compared to controls, being higher at the primary stage of VF loss, whereas normal levels have also been described $(44,46)$. Other studies have revealed abnormal ET-1 levels only following a change in body position or cold stimulation, suggesting that vascular dysregulation is probably involved in NTG-related GON $(45,48)$.

Su et al reported a generalized endothelial dysfunction in patients with NTG, by utilizing the brachial artery ultrasound assessment of endothelium-dependent flow-mediated vasodilation (49). Henry et al observed an altered peripheral vasodilation, caused by abnormal vascular response to endothelial vasoregulatory factors, due to impaired properties of ET receptors (50). Buckley et al, via cutaneous artery biopsies in patients with NTG, identified a defect in the release of vasodilating factors and enhanced sensitivity to ET-1, contributing to vasospasm (29). These findings demonstrate a systemic endothelium-derived vascular dysfunction in NTG. The structural and functional affinity between ocular and acral vasculature implies a similar dysfunction causing OBF disturbance in NTG (34). Of note, ET-1 largely exerts its vasoconstrictive effects on retinal microcirculation, and vascular inadequacy in posterior ciliary arteries supplying $\mathrm{ONH}$ has been indicated through color Doppler imaging (46), suggesting that such a local ET-1-dependent dysregulation could negatively affect $\mathrm{OBF}$ in the $\mathrm{ONH}$ and adjacent retina (22).

FS is the most important cause of vascular dysregulation in NTG (27). An endothelial dysfunction presenting high ET-1 and low NO plasmatic levels, may be the basis of FS, an imbalance that could disrupt $\mathrm{OBF}$, particularly in the $\mathrm{ONH}$, through irregular retrobulbar vasoconstriction (47). Moreover, an endothelial dysfunction has been reported in migraines (51). Plasma ET-1 levels have been positively associated with the resistivity index of retrobulbar vessels, as well as with an 
improper neuro-endothelial function via vasospasm in NTG cases (47).

To sum up, these findings indicate that an endothelial dysfunction seems to be the connective factor between systemic or local vascular dysregulation and irregular retrobulbar hemodynamics including vasoconstriction, which can induce OBF impairment occurring either primarily, promoting vasospasm and GON, or secondarily as a result of these changes in NTG.

\section{Mechanical factors}

The mechanical pathogenesis of NTG includes IOP and lamina cribrosa.

The role of IOP. Although an elevated IOP leads to GON through a recognized pathophysiological pathway, the normal IOP range in NTG implies that other mechanisms may coexist inducing glaucomatous damage (5).

The 'Collaborative Normal-Tension Glaucoma Study', which was conducted among 145 patients with NTG, reported that a $30 \%$ IOP reduction, even though favorable, did not prevent the progression of VF defects, indicating that IOP was not solely involved in GON (52). Agnifili et al observed the presence of conjunctival epithelial microcysts in NTG cases using in vivo confocal microscopy, suggesting an alteration in aqueous humor hydrodynamics concerning trans-scleral outflow in NTG (53). Epidemiological studies have demonstrated that NTG is more prevalent in Asian (52-92\%) compared with Caucasian (30-39\%) glaucoma cases, possibly reflecting a demographically different tolerance and/or genetic susceptibility to IOP $(2,52)$. IOP evaluation through contact lens sensor has revealed notable IOP fluctuations, presenting nocturnal acrophase and prolonged IOP peaks in $80 \%$ of NTG individuals (54). High IOP peaks (>90 mV) have been linked to glaucomatous progression and IOP fluctuations can lead to OBF instability in view of disturbed autoregulation $(55,56)$. Furthermore, an elevated nocturnal IOP in the supine position may contribute to ONH and/or VF damage in NTG (57). FS, the major cause of vascular dysregulation, also prevalent among Asian populations, may play an important role in IOP-induced damage in NTG. Moreover, an altered ONH morphology has been demonstrated in patients with NTG, with deeper and larger optic disc cups than POAG cases (58). Various studies have reported a thinner central corneal thickness in NTG than POAG and normal individuals which is also associated with VF defects, although these findings are considered controversial (59-61).

Thus, the above-mentioned findings create the hypothesis of a lower threshold for IOP-related damage in some patients with NTG as regards epidemiology, ocular morphology and dysregulation, where normal IOP and its fluctuations can induce mechanical stress and axonal damage in $\mathrm{ONH}$.

The impact of lamina cribrosa. Lamina cribrosa (LC) is a thin mesh-like collagenous tissue containing non-myelinated RGC axons, forming a barrier between intraocular and orbital subarachnoid spaces (SAS). It has been hypothesized that the trans-laminar pressure gradient (TLPG), expressed as the difference between IOP and intracranial pressure (ICP), is associated with mechanical damage to the optic nerve fibers in NTG $(62,63)$.

An elevated retrograde TLPG through a reduction in ICP can induce optic nerve damage, either baro-traumatically or through damage to the capillaries, resulting in a posteriorly displaced LC (64). Ren et al indicated a significantly reduced ICP using lumbar puncture in NTG regarding POAG or normal individuals, in agreement with the above-mentioned theory (65). A meta-analysis also reported a significantly reduced ICP and elevated TLPG in NTG and POAG than in normal subjects (66). Furthermore, multivariate analyses have revealed that TLPG was positively associated with perimetric VF defects and negatively with the neuroretinal rim area in both glaucoma types $(65,66)$. Nevertheless, other studies on patients with NTG have argued that ICP is normal and that TLPG is not significantly associated with VF defects $(67,68)$. A recent prospective study on 13 NTG cases demonstrated a normal TLPG and ICP, presenting no association with VF defects (68). Therefore, the issue of TLPG in NTG pathogenesis remains a matter of debate. Future methodological improvements may provide a more accurate assessment of TLPG, clarifying its role in NTG.

Jonas et al described a distinct difference in the appearance of optic nerve head in highly myopic eyes (refraction more than -8.00 diopters), with significantly larger discs and of a more oval configuration, which may render highly myopic eyes more susceptible to nerve fibre loss (69).

ET-1 and its receptors may also interact with LC function. Rao et al described an altered function and expression of $\mathrm{ET}_{\mathrm{A}}$ and $\mathrm{ET}_{\mathrm{B}}$ receptors in $\mathrm{LC}$ cells following prolonged stimulation by ET-1 (70,71). This implies that high ET-1 levels, a frequent observation in NTG cases, may affect LC via the remodeling of the extracellular matrix (ECM), thus causing LC deformation. An impaired LC structure and function can influence local RGC axons, astrocytes and capillaries, enhancing sensitivity to IOP-related stress in NTG (63).

\section{Obstructive sleep apnea/hypopnea syndrome}

There is recent evidence to suggest the involvement of obstructive sleep apnea/hypopnea syndrome (OSAHS) in NTG-related GON (72). OSAHS is characterized by upper airway obstruction during sleep. NTG is particularly prevalent among patients with OSAHS. Elevated IOP, VF disruption, glaucomatous disc alterations and thinning of the retinal nerve fiber layer have been reported in OSAHS cases $(72,73)$. GON pathogenesis in OSAHS includes both vascular and mechanical factors (72).

Repetitive sustained upper airway obstruction leads to recurrent hypoxemia (and thus hypoxia) and hypercapnia, in addition to increased vascular resistance which derives from enhanced sympathetic stimulation. Transient hypoxia combined with increased vascular resistance can harm the vascular endothelium, thus producing endothelial dysfunction and impaired autoregulation, possibly disturbing blood flow to the optic nerve and retina (74). Such an unstable oxygen concentration can directly cause insults to the optic nerve fibers, or indirectly via reperfusion and subsequent oxidative stress and inflammation (75). A diminished cerebral perfusion pressure may also affect blood flow to the optic nerve (76). Moreover, patients with OSAHS present an IOP nocturnal 
acrophase, which is associated with the supine position and immoderate orbital adipose tissue due to obesity $(73,77)$. Elastic fiber depletion in LC is also observed in patients with OSAHS, increasing the glaucomatous risk (72).

\section{The neurovascular hypothesis of RGC damage in NTG}

RGC cells and their axons, endothelium and glial cells, such as astrocytes, form a 'neurovascular unit', which contributes to the homeostasis of the microenvironment and OBF in $\mathrm{ONH}$ and retina, via vascular autoregulation, glial support, balance between ET-1 and NO, trophic supply, proper blood-brain barrier (BBB) and controlled immunity (19,78-80). Any disruption in these factors, mostly due to IOP-independent mechanisms, can damage the $\mathrm{ONH}$ and retina, resulting in NTG-related GON.

A primary pathogenetic step seems to be the OBF instability leading to RGC loss $(78,81)$. As demonstrated above, FS, migraines, vascular diseases, OSAHS, nocturnal systemic hypotension, IOP fluctuations and LC deformation induce OPP impairment and vascular dysregulation through complex mechanisms, thus resulting in an unstable OBF, a prominent finding of NTG $(9,22,25)$. A common characteristic of dysregulation in these conditions is an interplay between vasospasm and an ET-1-dependent endothelial dysfunction, occurring either primary or secondary to other changes, which can harm autoregulation and increase $\mathrm{ONH}$ susceptibility to vascular challenges (22). It should be noted that in particular, the short posterior ciliary arteries supplying the ONH and choroid are more sensitive to OPP alterations and vascular dysregulation than the central retinal artery, possibly indicating $\mathrm{ONH}$ as the initial location of damage (82). Although an improper OBF can directly lead to optic nerve atrophy and RGC loss through major sustained hypoxic insults, creating tissue infarction, such events rarely occur in NTG. Therefore, it is a mild, repetitive and reversible hypoxic pattern, namely an unstable oxygen tissue supply, as a result of oxygen saturation fluctuation due to impaired OBF and OSAHS, which contributes to glaucomatous damage. This phenomenon is known as ischemia-reperfusion injury (IRI) $(35,36)$. The main effect of IRI is the induction of chronic oxidative stress, particularly in local mitochondria of RGCs and their axons $(36,83)$.

Oxidative stress is a major factor of NTG-related GON. The reduction in the oxygen concentration impairs electron flow in mitochondrial complexes, which results in the formation of free radicals or reactive oxygen species (ROS), mainly superoxide $\left(\mathrm{O}_{2}^{-}\right)$, increasing the hydrogen peroxide $\left(\mathrm{H}_{2} \mathrm{O}_{2}\right)$ concentration. $\mathrm{H}_{2} \mathrm{O}_{2}$ further impairs electron flow and increases ROS production, leading to mitochondrial dysfunction. High or sustained ROS levels induce oxidative damage to the mitochondria, as well as to cellular proteins and DNA, causing insults to RGCs and their axons $(84,85)$. The upregulated expression of proteosome $20 \mathrm{~S} \alpha$ subunit and numerous DNA breaks in circulating lymphocytes in glaucoma cases support the hypothesis of oxidative stress involvement in GON (86). In addition, hypoxia and oxidative stress upregulates hypoxia-inducible factor- $1 \alpha$ (HIF-1 $\alpha)$ in the optic nerve and retina, which stimulates p53 and caspase, leading to RGC apoptosis (87). RGC axons in ONH, particularly in the prelaminar region, are mostly non-myelinated and consequently present high density of mitochondria due to high energy demands. Thus, ONH is the major site of mitochondrial dysfunction as a result of oxidative stress creating energy deficiency (35). LC cells also demonstrate significant mitochondrial dysfunction and enhanced ROS production with impaired antioxidant capacity in glaucoma (88).

Concurrently, glial cells vigorously respond to microenvironment alterations, leading to gliosis (35). Gliosis is defined as an activation of glial cells presenting hypertrophy and proliferation. Mechanical stress (IOP fluctuations, LC deformation and increased TLPG), through the release of epidermal growth factor receptor (EGFR), elevated ET-1, IRI, ROS and oxidative stress can result in gliosis $(35,85)$. Indeed, stimulated astrocytes and microglia have been observed in glaucoma, promoting demyelination and damage to the axons (89). Apart from $\mathrm{ONH}$, gliosis also occurs in the retina through chronic stimulation of Müller cells, causing the apoptosis of RGC bodies via degenerative and inflammatory processes. Activated glial cells further disrupt the microenvironment in $\mathrm{ONH}$ and retina through the release of various factors being involved in neurodegeneration (90). The astrocytic release of ET-1 further impairs OBF, mediates RGC apoptosis and disrupts axonal transport (91). The glial production of tumor necrosis factor- $\alpha(\mathrm{TNF}-\alpha)$ and interleukin-1 $\beta$ (IL-1 $\beta$ ) can induce the apoptosis of RGC and axons through binding to TNF receptor and the activation of nerve factor $(\mathrm{NF})-\kappa \mathrm{B}$, respectively, leading to an enhanced inflammatory response (90).

Moreover, the cytokine-mediated upregulation of NO synthase-2 (NOS-2) by glial cells has been shown to elevate local NO levels (35). NO, although harmless, diffuses into RGC axons in $\mathrm{ONH}$ where it reacts with high levels of superoxide, due to intense local mitochondrial dysfunction and oxidative stress, creating peroxynitrite $\left(\mathrm{ONOO}^{-}\right)$. Peroxynitrite, as well as superoxide, are able to diffuse along the RGC axons into both the retina and lateral geniculate nucleus, leading to neuronal apoptosis through oxidative DNA damage (92).

Glutamate seems to play an important role in GON. The extracellular glutamate concentration in retina is maintained below neurotoxic levels by uptake via glutamate/aspartate transporter (GLAST) into Müller glial cells. Oxidative stress could increase extracellular glutamate due to ROS-induced reuptake failure of glutamate, a fact which is evident in NTG animal studies. An impaired glial GLAST function, possibly due to genetic polymorphisms may be responsible for elevated glutamate levels, as reported in transgenic mice, although in vivo evidence in NTG is needed $(84,92)$. Glutamate neurotoxicity is mediated through the over-stimulation of $N$-methyl-D-asparate (NMDA) membrane receptors by glutamate in RGCs enhancing intracellular $\mathrm{Ca}^{2+}$ influx, which activates various apoptotic pathways, damaging the mitochondria, endoplasmic reticulum and DNA (93). Additionally, an NMDA-related activation of NF- $\mathrm{NB}$ has been detected in Müller glial cells, leading to TNF- $\alpha$ formation and RGC apoptosis via TNFR signaling and $\mathrm{Ca}^{2+}$ influx (94). This glutamate-induced damage is known as 'excitotoxicity'.

Oxidative stress, IRI and cell damage, upregulate ET-1 release in NTG, as a result of activated astrocytes and endothelial dysfunction $(36,91)$. There are diverse mechanisms of ET-1-related GON in NTG. ET-1 induces chronic ONH ischemia through irregular vasoconstriction and enhances 


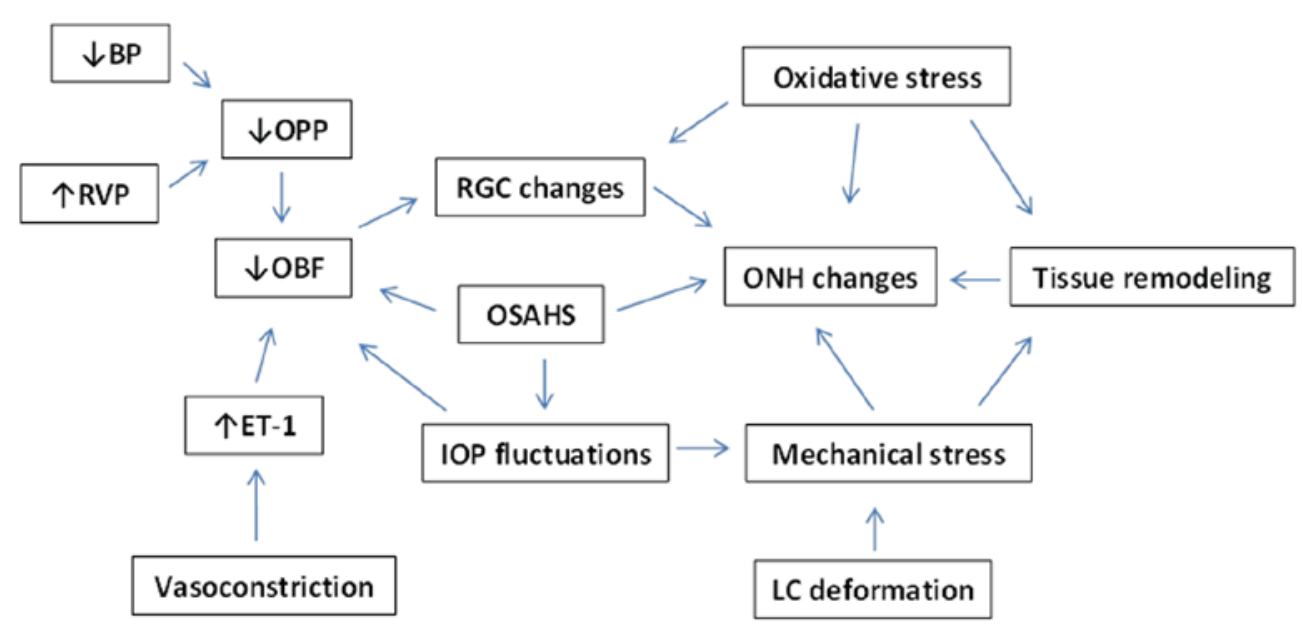

Figure 1. Factors contributing to normal-tension glaucoma (NTG). BP, blood pressure; RVP, retinal venous pressure; OPP, ocular perfusion pressure; OBF, ocular blood flow; ET-1, endothelin-1; RGC, retinal ganglion cell; OSAHS, obstructive sleep apnea/hypopnea syndrome; IOP, intraocular pressure; ONH, optic nerve head; LC, lamina cribrosa.

glutamate toxicity in retina through $\mathrm{ET}_{\mathrm{A}}$ receptors. In addition, ET-1 promotes astrocyte activation and amplifies neuroinflammation through $\mathrm{ET}_{\mathrm{B}}$ receptors $(18,44)$. Combined $\mathrm{ET}_{\mathrm{A}}$ and $\mathrm{ET}_{\mathrm{B}}$ stimulation by increased ET-1 promotes superoxide synthesis and NOS upregulation (95), disturbs retrograde and anterograde axonal transport in optic nerve, contributes to ECM remodeling in $\mathrm{ONH}$, particularly in LC $(70,71)$, and causes RGC apoptosis $(91,93,95)$.

Moreover, tissue remodeling triggered by activated astrocytes and mechanical stress occurs concurrently to the damage in RGC and axons, leading to the overproduction of metalloproteinases (MMPs), which enzymatically alter ECM morphology and composition (63). Upregulated MMP-2 and MMP-9 levels have been detected both locally in ONH, as well as in circulating lymphocytes in glaucoma (96). Therefore, tissue remodeling contributes to ONH excavation, as well as LC bowing and deformation (27).

BBB damage has been indicated in NTG (97). Capillaries of the retina and $\mathrm{ONH}$ present a complete BBB, with endothelial tight-junctions between adjacent endothelial cells. However, capillaries in prelaminar region of $\mathrm{ONH}$ have an improper $\mathrm{BBB}$, and choroid vessels are highly fenestrated (98). Although elevated plasma ET-1 levels exert a neutral effect in retinal and ONH vessels when BBB is intact, ET-1 can diffuse from choroid capillaries into the $\mathrm{ONH}$ and adjacent retina, resulting in vasoconstriction, impaired ONH blood flow, increased RVP and weakening of endothelial tight-junctions. The hypoxic retina upregulates HIF-1 $\alpha$, stimulating the release of ET-1 in local vessels, which also leads to vasoconstriction and damage to the BBB (97). Simultaneous ET-1 and MMP-9 diffusion from the choroid into the ONH can disrupt endothelial tight-junctions and basal membrane with the subsequent leak of erythrocytes, clinically observed as optic disc hemorrhage in NTG $(97,99)$. BBB damage also includes the extravasation of proteins, tissue deposition of toxins such as $A \beta$, and the release of plasma ET-1 and MMP-9 promoting BBB damage $(96,100)$.

The aforementioned factors may be involved in RGC loss and in the synthesis of inflammatory antigens or cytokines. Moreover, interplay between oxidative stress and damage, ROS secretion and gliosis can cause an aberrant immune response due to the loss of normal immunosuppression, increased antigenity, and increased antigen presentation or exposure. All of these combined can result in immune dysregulation and possibly trigger autoimmune neurodegenerative processes $(87,90)$. Indeed, the presence of elevated levels of anti-phosphatidylserine and anti-rhodopsin antibodies in the serum of NTG patients has been reported, pointing towards an autoimmune aspect of NTG pathogenesis (27).

Finally, mechanical and oxidative stress, astrocytes and microglia activation, ET-1, lateral geniculate nucleus (LGN) degeneration and axonal damage disrupt the signaling and bioactivity of neuronal growth factors, including brain-derived neurotrophic factor (BDNF), vascular endothelial growth factor (VEGF) and nerve growth factor (NGF), causing a diminished neurotrophic support negatively impacting axonal myelination in ONH and survival of RGC in the retina (101).

Fig. 1 summarizes the interaction of the aforementioned mechanisms in NTG pathogenesis.

\section{Genetic associations in NTG}

NTG is a heterogeneous disease, involving multiple genes in its pathogenesis. The presence of a family history in NTG cases suggests a possible genetic predisposition to NTG (102).

Variants in genes including WD repeat-containing protein 36 (WDR36), myocilin (MYOC) and optineurin (OPTN), are considered causative for NTG, although further evidence is required $(103,104)$. The association between OPTN gene alterations in NTG cases and families has been reported (105). $O P T N$ plays a neuroprotective, as well as an IOP-controlling role. Studies have also revealed a possible link between OPTN, NTG and Alzheimer's disease $(102,106)$. Mutations in the optic atrophy type $1(O P A l)$ gene may be related to hereditary NTG. OPA1 is involved in mitochondrial function, protecting RGC from retinal mechanical stress. OPAI polymorphisms in NTG have been confirmed, which can induce RGC apoptosis probably via mitochondrial dysfunction $(107,108)$. The duplication of TANK binding kinase 1 (TBK1) gene in glaucoma 1P (GLC1P) locus on 12q14 
Table I. Glaucoma-associated candidate genes.

\begin{tabular}{|c|c|c|c|c|}
\hline \multirow[b]{2}{*}{ Gene } & \multirow{2}{*}{$\begin{array}{l}\text { Chromosomal } \\
\text { location }\end{array}$} & \multicolumn{2}{|c|}{ Glaucoma subtype } & \multirow[b]{2}{*}{ Author (Ref.), year } \\
\hline & & NTG & POAG & \\
\hline WDR36 (WD repeat-containing protein 36) & $5 q 22.1$ & & + & $\begin{array}{l}\text { Monemi et al (132), } 2005 \\
\text { Rangachari et al (135), } 2011 \\
\text { Kumar et al (129), } 2016\end{array}$ \\
\hline MYOC (myocilin) & $1 q 24.3$ & + & + & Stone et al (139), 1997 \\
\hline OPTN (optineurin) & $10 \mathrm{p} 13$ & + & + & $\begin{array}{l}\text { Rezaie et al (136), } 2002 \\
\text { Kumar et al (129), } 2016\end{array}$ \\
\hline TBK1 (TANK-binding kinase 1) & $12 \mathrm{q} 14$ & & + & Fingert et al (127), 2011 \\
\hline$G L C 1 B$ (glaucoma 1, open angle, B) & 2 cen-q13 & & $\begin{array}{l}\text { APOAG } \\
+\end{array}$ & Stoilova et al (138), 1996 \\
\hline ASB10 (GLC1F, open-angle glaucoma-1F) & $7 q 36.1$ & & + & $\begin{array}{l}\text { Wirtz et al (140),1999 } \\
\text { Pasutto et al (134), } 2012\end{array}$ \\
\hline EDNRA (endothelin receptor, type A) & $4 q 31.22-q 31.23$ & & + & Janssen et al (128), 2013 \\
\hline TLR4 (Toll-like receptor 4) & $9 q 33.1$ & + & + & Janssen et al (128), 2013 \\
\hline OPAl (optic atrophy 1 ) & $3 q 29$ & + & & $\begin{array}{l}\text { Lascaratos et al (130), } 2012 \\
\text { Yu-Wai-Man et al (142), } 2010\end{array}$ \\
\hline MFN1 (mitofusin 1) & $3 q 26.33$ & & + & Lascaratos et al (130), 2012 \\
\hline MFN2 (mitofusin 2) & $1 \mathrm{p} 36.22$ & & + & Lascaratos et al (130), 2012 \\
\hline PARL (presenilin-associated rhomboid-like protein) & $3 q 27.1$ & & + & Lascaratos et al (130), 2012 \\
\hline$R O R C$ (RAR-related orphan receptor $\mathrm{C}$ gene) & $1 \mathrm{q} 21.3$ & + & & Fraenkl et al (112), 2013 \\
\hline MMP-9 (matrix metallopeptidase 9) & $20 q 13.12$ & + & + & $\begin{array}{l}\text { Golubnitschaja et al (96), } 2004 \\
\text { Sahay et al (137), } 2017\end{array}$ \\
\hline MMP-14 (matrix metallopeptidase 14) & $14 q 11.2$ & + & + & Golubnitschaja et al (96), 2004 \\
\hline SRBDI (S1 RNA binding domain 1) & $2 \mathrm{p} 21$ & + & & $\begin{array}{l}\text { Writing Committee for the } \\
\text { Normal-Tension Glaucoma Genetic } \\
\text { Study Group of Japan Glaucoma } \\
\text { Society et al (117), } 2010\end{array}$ \\
\hline ELOVL5 (ELOVL fatty acid elongase 5) & $6 \mathrm{p} 12.1$ & + & & $\begin{array}{l}\text { Writing Committee for the } \\
\text { Normal-Tension Glaucoma Genetic } \\
\text { Study Group of Japan Glaucoma } \\
\text { Society et al (117), } 2010\end{array}$ \\
\hline$C D K N 2 B$ (cyclin-dependent kinase inhibitor 2B) & $9 \mathrm{p} 213$ & + & & Mabuchi et al (131), 2012 \\
\hline ATOH7 (atonal, Drosophila, homolog of, 7) & $10 \mathrm{q} 21.3$ & + & & Mabuchi et al (131), 2012 \\
\hline$D C L K 1$ (doublecortin-like kinase 1) & $13 q 13.3$ & + & $\begin{array}{l}\text { HTG } \\
+\end{array}$ & Mabuchi et al (131), 2012 \\
\hline RERE (RE repeats-encoding gene) & $1 \mathrm{p} 36.23$ & + & $\begin{array}{l}\text { HTG } \\
+\end{array}$ & Mabuchi et al (131), 2012 \\
\hline $\begin{array}{l}R P G R I P 1 \text { (retinitis pigmentosa GTPase } \\
\text { regulator-interacting protein } 1 \text { ) }\end{array}$ & $14 q 11.2$ & + & $\begin{array}{c}\text { JOAG } \\
+\end{array}$ & Fernández-Martínez et al (126), 2011 \\
\hline$A P O E$ (apolipoprotein $\mathrm{E}$ ) & $19 \mathrm{q} 13.32$ & + & & $\begin{array}{l}\text { Janssen et al (128), } 2013 \\
\text { Nowak et al (133), } 2015\end{array}$ \\
\hline$H S P 70-1 A$ (heat shock 70-kDa protein $1 \mathrm{~A}$ ) & $6 \mathrm{p} 21.33$ & + & $\begin{array}{l}\text { PACG } \\
\quad+\end{array}$ & $\begin{array}{l}\text { Ayub et al (125), } 2010 \\
\text { Nowak et al (133), } 2015\end{array}$ \\
\hline MTHFR (5,10-methylenetetrahydrofolate reductase) & $1 \mathrm{p} 36.22$ & + & + & Woo et al (141), 2009 \\
\hline
\end{tabular}

POAG, primary open-angle glaucoma; NTG, normal-tension glaucoma; APOAG, adult-onset primary open-angle glaucoma; JOAG, juvenile open-angle glaucoma; HTG, high-tension glaucoma; PACG, primary angle closure glaucoma. 
chromosome has also been identified in familial NTG cases. $T B K 1$ is expressed in RGC and retinal microcirculation, and can thus contribute to apoptosis and vascular impairment in NTG through a dysregulated expression (109). Polymorphisms of the endothelin receptor type $\mathrm{A}(E D N R A)$ gene of $\mathrm{ET}_{\mathrm{A}}$ receptor, such as $\mathrm{C}+70 \mathrm{G}$, have been related to more severe VF defects in NTG, also being revealed in a Korean NTG population study (110). Various single nucleotide polymorphisms (SNPs) in the toll-like receptor 4 (TLR4) gene have been indicated in NTG cases in Japanese contrary to Korean populations. Since TLR4 mediates immune responses, such alterations may result in aberrant immunity and autoimmune phenomena in patients with NTG (111). Human leukocyte antigen (HLA) class II variants have also been associated with NTG, contributing to autoimmunity. RAR-related orphan receptor $\mathrm{C}(R O R C)$ gene upregulation in blood lymphocytes has been detected in patients with NTG, which can promote apoptosis and improper immunity (112). As regards oxidative stress and mitochondrial dysfunction, a variety of mitochondrial irregularities and mitochondrial DNA alterations have been determined in patients with NTG, including a Korean population, pointing towards a genetic profile of this condition (113). Concerning tissue remodeling, the upregulated gene expression of $M M P-9$ and $M M P-14$ has been detected in patients with NTG, as well as in circulating lymphocytes (96). Numerous other candidate gene variants have been reported in NTG, such as glaucoma 1B $(G L C 1 B)(114)$, glaucoma $1 \mathrm{~F}(G L C l F)$ (115), mitofusin-1 (MFN1) (116), mitofusin-2 (MFN2) (116), S1 RNA-binding domain (SRBD1) (117), presenilin-associated rhomboid-like (PARL) (116) and fatty acid elongase 5 (ELOVL5) (117).

Studies on NTG-related models of transgenic mice have helped to further elucidate NTG pathogenesis. E50K mutant transgenic mice overexpressing OPTN have demonstrated RGC loss, also reflecting the role of oxidative stress in NTG (118). WDR36-mutant mice exhibit axonal growth impairment, resulting in progressive RGC degeneration (119). Mice with the OPA1 variant exhibit RGC death and ONH atrophy (120). The endothelial overexpression of ET-1 in TET-1 mice reveals the degeneration of RGC and their axons, BBB damage and retinal gliosis, implying a vascular-related component of NTG (121). Damage to the RGCs and their axons has been reported in P301S and amyloid precursor protein/presenilin 1 (APP/PS1) mice, indicating an association between NTG and Alzheimer's disease $(122,123)$. GLAST and excitatory carrier-1 (EAAC1) deficient mice present impulsive RGC loss and optic nerve degeneration with normal IOP. Furthermore, mice deficient with apoptosis signal-regulating kinase-1 (Ask-1) are more tolerant to ischemia, exhibit diminished RGC and axonal loss, and mild VF defects, suggesting Ask-1 as a potential target for NTG therapy (124). Table I summarizes the genes reported to be associated with NTG, to the best of the our knowledge.

\section{Conclusions}

All things considered, NTG is a multifactorial disease, leading to progressive GON without an elevated IOP. Vascular dysregulation may be the key of vascular pathogenesis resulting in $\mathrm{OBF}$ instability in $\mathrm{ONH}$, retina and choroid through an interplay between retrobulbar vasospasm and endothelial dysfunction. Mechanical factors, such as increased sensitivity to IOP fluctuations, LC dysfunction and TLPG also play a significant role. OSAHS and may also be a mixed risk factor for NTG. All these factors, through oxidative stress, gliosis, excitotoxicity, ET-1 upregulation, BBB damage, abnormal immunity and deficient trophic support can promote axonal damage and RGC apoptosis via several extrinsic and intrinsic pathways. In addition, current literature indicates a strong genetic component in NTG, with genes significantly contributing to its pathogenesis. Nevertheless, NTG remains a complex disease. Further studies are warranted to focus on clarifying the mechanisms responsible for NTG-related GON and its genetic basis, aiding to the development of diagnostic and therapeutic strategies.

\section{Acknowledgements}

Not applicable.

\section{Funding}

No funding was received.

\section{Availability of data and materials}

Not applicable.

\section{Authors' contributions}

AT conceived and designed the study. AT, IK, CT and GD researched the literature, performed analysis of data and drafted the manuscript. GNG, ETD, DAS and CSS researched the literature, performed the analysis of the data and critically revised the article for important intellectual content. All authors have read and approved the final manuscript.

\section{Ethics approval and consent to participate}

Not applicable.

\section{Patient consent for publication}

Not applicable.

\section{Competing interests}

DAS is the Editor-in-Chief for the journal, but had no personal involvement in the reviewing process, or any influence in terms of adjudicating on the final decision, for this article. The other authors declare that they have no competing interests.

\section{References}

1. Lee BL, Bathija R and Weinreb RN: The definition of normal-tension glaucoma. J Glaucoma 7: 366-371, 1998.

2. Cho HK and Kee C: Population-based glaucoma prevalence studies in Asians. Surv Ophthalmol 59: 434-447, 2014.

3. Budak Y and Akdogan M: Retinal ganglion cell death. In: Glaucoma-Basic and Clinical Concepts. Rumelt S (ed). InTech, Rijeka, pp33-56, 2011. https://www.intechopen.com/books/ glaucoma-basic-and-clinical-concepts/retinal-ganglion-celldeath. 
4. Drance S, Anderson DR and Schulzer M; Collaborative Normal-Tension Glaucoma Study Group: Risk factors for progression of visual field abnormalities in normal-tension glaucoma. Am J Ophthalmol 131: 699-708, 2001.

5. Flammer J, Orgül S, Costa VP, Orzalesi N, Krieglstein GK, Serra LM, Renard JP and Stefánsson E: The impact of ocular blood flow in glaucoma. Prog Retin Eye Res 21: 359-393, 2002.

6. Grunwald JE, Piltz J, Hariprasad SM and DuPont J: Optic nerve and choroidal circulation in glaucoma. Invest Ophthalmol Vis Sci 39: 2329-2336, 1998.

7. Quaranta L and Floriani I: The rate of progression and ocular perfusion pressure in the Low-pressure Glaucoma Treatment Study. Am J Ophthalmol 152: 880-881, author reply 880-881, 2011.

8. Sung KR, Cho JW, Lee S, Yun SC, Choi J, Na JH, Lee Y and Kook MS: Characteristics of visual field progression in medically treated normal-tension glaucoma patients with unstable ocular perfusion pressure. Invest Ophthalmol Vis Sci 52: 737-743, 2011.

9. Choi J, Kim KH, Jeong J, Cho HS, Lee CH and Kook MS: Circadian fluctuation of mean ocular perfusion pressure is a consistent risk factor for normal-tension glaucoma. Invest Ophthalmol Vis Sci 48: 104-111, 2007.

10. Okumura Y, Yuki K and Tsubota K: Low diastolic blood pressure is associated with the progression of normal-tension glaucoma. Ophthalmologica 228: 36-41, 2012.

11. Gasser P and Flammer J: Blood-cell velocity in the nailfold capillaries of patients with normal-tension and high-tension glaucoma. Am J Ophthalmol 111: 585-588, 1991.

12. Flammer J: The vascular concept of glaucoma. Surv Ophthalmol 38 (Suppl): S3-S6, 1994.

13. Flammer J and Mozaffarieh M: Autoregulation, a balancing act between supply and demand. Can J Ophthalmol 43: 317-321, 2008.

14. Abegão Pinto L, Vandewalle E and Stalmans I: Disturbed correlation between arterial resistance and pulsatility in glaucoma patients. Acta Ophthalmol 90: e214-e220, 2012.

15. Galassi F, Sodi A, Ucci F, Renieri G, Pieri B and Baccini M: Ocular hemodynamics and glaucoma prognosis: A color Doppler imaging study. Arch Ophthalmol 121: 1711-1715, 2003.

16. Emre M, Orgül S, Gugleta K and Flammer J: Ocular blood flow alteration in glaucoma is related to systemic vascular dysregulation. Br J Ophthalmol 88: 662-666, 2004.

17. Pache M, Kaiser HJ, Akhalbedashvili N, Lienert C, Dubler B, Kappos L and Flammer J: Extraocular blood flow and endothelin-1 plasma levels in patients with multiple sclerosis. Eur Neurol 49: 164-168, 2003.

18. Chauhan BC, LeVatte TL, Jollimore CA, Yu PK, Reitsamer HA Kelly ME, Yu DY, Tremblay F and Archibald ML: Model of endothelin-1-induced chronic optic neuropathy in rat. Invest Ophthalmol Vis Sci 45: 144-152, 2004.

19. Flammer J and Mozaffarieh M: What is the present pathogenetic concept of glaucomatous optic neuropathy? Surv Ophthalmol 52 (Suppl 2): S162-S173, 2007.

20. Furlanetto RL, De Moraes CG, Teng CC, Liebmann JM, Greenfield DS, Gardiner SK, Ritch R and Krupin T; Low-Pressure Glaucoma Treatment Study Group: Risk factors for optic disc hemorrhage in the Low-Pressure Glaucoma Treatment Study. Am J Ophthalmol 157: 945-952, 2014.

21. Orgül S, Kaiser HJ, Flammer J and Gasser P: Systemic blood pressure and capillary blood-cell velocity in glaucoma patients: A preliminary study. Eur J Ophthalmol 5: 88-91, 1995.

22. Moore D, Harris A, Wudunn D, Kheradiya N and Siesky B Dysfunctional regulation of ocular blood flow: A risk factor for glaucoma? Clin Ophthalmol 2: 849-861, 2008

23. Charlson ME, de Moraes CG, Link A, Wells MT, Harmon G, Peterson JC, Ritch R and Liebmann JM: Nocturnal systemic hypotension increases the risk of glaucoma progression. Ophthalmology 121: 2004-2012, 2014.

24. Bowe A, Grünig M, Schubert J, Demir M, Hoffmann V, Kütting F, Pelc A and Steffen HM: Circadian variation in arterial blood pressure and glaucomatous optic neuropathy - a systematic review and meta-analysis. Am J Hypertens 28 : 1077-1082, 2015.

25. Lee J, Choi J, Jeong D, Kim S and Kook MS: Relationship between daytime variability of blood pressure or ocular perfusion pressure and glaucomatous visual field progression. Am J Ophthalmol 160: 522-537.e1, 2015.

26. Flammer J, Konieczka K and Flammer AJ: The primary vascular dysregulation syndrome: Implications for eye diseases. EPMA J 4: 14,2013
27. Konieczka K, Ritch R, Traverso CE, Kim DM, Kook MS, Gallino A, Golubnitschaja O, Erb C, Reitsamer HA, Kida T, et al: Flammer syndrome. EPMA J 5: 11, 2014.

28. Cursiefen C, Wisse M, Cursiefen S, Jünemann A, Martus P and Korth M: Migraine and tension headache in high-pressure and normal-pressure glaucoma. Am J Ophthalmol 129: 102-104, 2000.

29. Buckley C, Hadoke PW, Henry E and O'Brien C: Systemic vascular endothelial cell dysfunction in normal pressure glaucoma. Br J Ophthalmol 86: 227-232, 2002.

30. Teuchner B, Orgül S, Ulmer H, Haufschild T and Flammer J: Reduced thirst in patients with a vasospastic syndrome. Acta Ophthalmol Scand 82: 738-740, 2004.

31. Gherghel D, Orgül S, Gugleta K and Flammer J: Retrobulbar blood flow in glaucoma patients with nocturnal over-dipping in systemic blood pressure. Am J Ophthalmol 132: 641-647, 2001.

32. Wunderlich K, Zimmerman C, Gutmann H, Teuchner B, Flammer J and Drewe J: Vasospastic persons exhibit differential expression of ABC-transport proteins. Mol Vis 9: 756-761, 2003

33. Pache M, Kräuchi K, Cajochen C, Wirz-Justice A, Dubler B, Flammer J and Kaiser HJ: Cold feet and prolonged sleep-onset latency in vasospastic syndrome. Lancet 358: 125-126, 2001.

34. Mozaffarieh M, Osusky R, Schotzau A and Flammer J: Relationship between optic nerve head and finger blood flow. Eur J Ophthalmol 20: 136-141, 2010.

35. Mozaffarieh M and Flammer J: New insights in the pathogenesis and treatment of normal tension glaucoma. Curr Opin Pharmacol 13: 43-49, 2013

36. Flammer J: Glaucomatous optic neuropathy: A reperfusion injury. Klin Monbl Augenheilkd 218: 290-291, 2001 (In German).

37. Gugleta K, Zawinka C, Rickenbacher I, Kochkorov A, Katamay R, Flammer J and Orgul S: Analysis of retinal vasodilation after flicker light stimulation in relation to vasospastic propensity. Invest Ophthalmol Vis Sci 47: 4034-4041, 2006.

38. Gugleta K, Orgül S, Hasler PW, Picornell T, Gherghel D and Flammer J: Choroidal vascular reaction to hand-grip stress in subjects with vasospasm and its relevance in glaucoma. Invest Ophthalmol Vis Sci 44: 1573-1580, 2003

39. Nitta K: Disc hemorrhage is a sign of progression in normal-tension glaucoma. J Glaucoma 21: 276, 2012.

40. Corbett JJ, Phelps CD, Eslinger P and Montague PR: The neurologic evaluation of patients with low-tension glaucoma. Invest Ophthalmol Vis Sci 26: 1101-1104, 1985.

41. Kruit MC, Launer LJ, Ferrari MD and van Buchem MA: Infarcts in the posterior circulation territory in migraine. The population-based MRI CAMERA study. Brain 128: 2068-2077, 2005.

42. Haefliger IO, Flammer J, Bény JL and Lüscher TF: Endothelium-dependent vasoactive modulation in the ophthalmic circulation. Prog Retin Eye Res 20: 209-225, 2001

43. Toda $\mathrm{N}$ and Nakanishi-Toda M: Nitric oxide: Ocular blood flow, glaucoma, and diabetic retinopathy. Prog Retin Eye Res 26: 205-238, 2007.

44. Sugiyama T, Moriya S, Oku H and Azuma I: Association of endothelin-1 with normal tension glaucoma: Clinical and fundamental studies. Surv Ophthalmol 39 (Suppl 1): S49-S56, 1995.

45. Kaiser HJ, Flammer J, Wenk M and Lüscher T: Endothelin-1 plasma levels in normal-tension glaucoma: Abnormal response to postural changes. Graefes Arch Clin Exp Ophthalmol 233: 484-488, 1995

46. Cellini M, Possati GL, Profazio V, Sbrocca M, Caramazza N and Caramazza R: Color Doppler imaging and plasma levels of endothelin-1 in low-tension glaucoma. Acta Ophthalmol Scand Suppl 224 (S224): 11-13, 1997.

47. Galassi F, Giambene B and Varriale R: Systemic vascular dysregulation and retrobulbar hemodynamics in normal-tension glaucoma. Invest Ophthalmol Vis Sci 52: 4467-4471, 2011.

48. Nicolela MT, Ferrier SN, Morrison CA, Archibald ML, LeVatte TL, Wallace K, Chauhan BC and LeBlanc RP: Effects of cold-induced vasospasm in glaucoma: The role of endothelin-1. Invest Ophthalmol Vis Sci 44: 2565-2572, 2003.

49. Su WW, Cheng ST, Hsu TS and Ho WJ: Abnormal flow-mediated vasodilation in normal-tension glaucoma using a noninvasive determination for peripheral endothelial dysfunction. Invest Ophthalmol Vis Sci 47: 3390-3394, 2006.

50. Henry E, Newby DE, Webb DJ, Hadoke PWF and O'Brien CJ: Altered endothelin-1 vasoreactivity in patients with untreated normal-pressure glaucoma. Invest Ophthalmol Vis Sci 47: 2528-2532, 2006. 
51. Hamed SA, Hamed EA, Ezz Eldin AM and Mahmoud NM: Vascular risk factors, endothelial function, and carotid thickness in patients with migraine: Relationship to atherosclerosis. J Stroke Cerebrovasc Dis 19: 92-103, 2010.

52. Collaborative Normal-Tension Glaucoma Study Group: The effectiveness of intraocular pressure reduction in the treatment of normal-tension glaucoma. Am J Ophthalmol 126: 498-505, 1998.

53. Agnifili L, Carpineto P, Fasanella V, Mastropasqua R, Zappacosta A, Di Staso S, Costagliola C and Mastropasqua L: Conjunctival findings in hyperbaric and low-tension glaucoma: An in vivo confocal microscopy study. Acta Ophthalmol 90: e132-e137, 2012.

54. Agnifili L, Mastropasqua R, Frezzotti P, Fasanella V, Motolese I, Pedrotti E, Di Iorio A, Mattei PA, Motolese E and Mastropasqua L: Circadian intraocular pressure patterns in healthy subjects, primary open angle and normal tension glaucoma patients with a contact lens sensor. Acta Ophthalmol 93: e14-e21, 2015.

55. De Moraes CG, Jasien JV, Simon-Zoula S, Liebmann JM and Ritch R: Visual field change and 24-hour IOP-related profile with a contact lens sensor in treated glaucoma patients. Ophthalmology 123: 744-753, 2016.

56. Choi J and Kook MS: Systemic and ocular hemodynamic risk factors in glaucoma. Biomed Res Int 2015: 141905, 2015.

57. Sakata R, Aihara M, Murata H, Saito H, Iwase A, Yasuda N and Araie M: Intraocular pressure change over a habitual 24-hour period after changing posture or drinking water and related factors in normal tension glaucoma. Invest Ophthalmol Vis Sci 54: 5313-5320, 2013.

58. Adlina AR, Alisa-Victoria K, Shatriah I, Liza-Sharmini AT and Ahmad MS: Optic disc topography in Malay patients with normal-tension glaucoma and primary open-angle glaucoma. Clin Ophthalmol 8: 2533-2539, 2014.

59. Copt RP, Thomas R and Mermoud A: Corneal thickness in ocular hypertension, primary open-angle glaucoma, and norma tension glaucoma. Arch Ophthalmol 117: 14-16, 1999.

60. Lee JW, Wong RL, Chan JC, Wong IY and Lai JS: Differences in corneal parameters between normal tension glaucoma and primary open-angle glaucoma. Int Ophthalmol 35: 67-72, 2015.

61. Cao KY, Kapasi M, Betchkal JA and Birt CM: Relationship between central corneal thickness and progression of visual field loss in patients with open-angle glaucoma. Can J Ophthalmol 47: $155-158,2012$

62. Jonas JB, Wang N and Yang D: Translamina cribrosa pressure difference as potential element in the pathogenesis of glaucomatous optic neuropathy. Asia Pac J Ophthalmol (Phila) 5: 5-10, 2016.

63. Burgoyne CF: A biomechanical paradigm for axonal insult within the optic nerve head in aging and glaucoma. Exp Eye Res 93: 120-132, 2011

64. Wostyn P, De Groot V, Van Dam D, Audenaert K and De Deyn PP: Senescent changes in cerebrospinal fluid circulatory physiology and their role in the pathogenesis of normal-tension glaucoma. Am J Ophthalmol 156: 5-14.e2, 2013.

65. Ren R, Jonas JB, Tian G, Zhen Y, Ma K, Li S, Wang H, Li B, Zhang $\mathrm{X}$ and Wang N: Cerebrospinal fluid pressure in glaucoma: A prospective study. Ophthalmology 117: 259-266, 2010.

66. Siaudvytyte L, Januleviciene I, Daveckaite A, Ragauskas A, Bartusis L, Kucinoviene J, Siesky B and Harris A: Literature review and meta-analysis of translaminar pressure difference in open-angle glaucoma. Eye (Lond) 29: 1242-1250, 2015.

67. Pircher A, Remonda L, Weinreb RN and Killer HE: Translaminar pressure in Caucasian normal tension glaucoma patients. Acta Ophthalmol 95: e524-e531, 2017.

68. Lindén C, Qvarlander S, Jóhannesson G, Johansson E, Östlund F Malm $\mathrm{J}$ and Eklund A: Normal-tension glaucoma has normal intracranial pressure: A prospective study ofintracranial pressure and intraocular pressure in different body positions. Ophthalmology 125: 361-368, 2018.

69. Jonas JB, Gusek GC and Naumann GO: Optic disk morphometry in high myopia. Graefes Arch Clin Exp Ophthalmol 226: 587-590, 1988.

70. Rao VR, Krishnamoorthy RR and Yorio T: Endothelin-1, endothelin A and B receptor expression and their pharmacological properties in GFAP negative human lamina cribrosa cells. Exp Eye Res 84: 1115-1124, 2007.

71. Rao VR, Krishnamoorthy RR and Yorio T: Endothelin-1 mediated regulation of extracellular matrix collagens in cells of human lamina cribrosa. Exp Eye Res 86: 886-894, 2008.
72. Pérez-Rico C, Gutiérrez-Díaz E, Mencía-Gutiérrez E, Díaz-de-Atauri MJ and Blanco R: Obstructive sleep apnea-hypopnea syndrome (OSAHS) and glaucomatous optic neuropathy. Graefes Arch Clin Exp Ophthalmol 252: 1345-1357, 2014.

73. Lin PW, Friedman M, Lin HC, Chang HW, Wilson M and Lin MC: Normal tension glaucoma in patients with obstructive sleep apnea/hypopnea syndrome. J Glaucoma 20: 553-558, 2011.

74. Karakucuk S, Goktas S, Aksu M, Erdogan N, Demirci S, Oner A, Arda H and Gumus K: Ocular blood flow in patients with obstructive sleep apnea syndrome (OSAS). Graefes Arch Clin Exp Ophthalmol 246: 129-134, 2008.

75. Nadeem R, Molnar J, Madbouly EM, Nida M, Aggarwal S, Sajid H, Naseem J and Loomba R: Serum inflammatory markers in obstructive sleep apnea: A meta-analysis. J Clin Sleep Med 9: 1003-1012, 2013

76. Thurtell MJ, Bruce BB, Newman NJ and Biousse V: An update on idiopathic intracranial hypertension. Rev Neurol Dis 7: e56-e68, 2010.

77. Hara T, Hara T and Tsuru T: Increase of peak intraocular pressure during sleep in reproduced diurnal changes by posture. Arch Ophthalmol 124: 165-168, 2006.

78. Carvey PM, Hendey B and Monahan AJ: The blood-brain barrier in neurodegenerative disease: A rhetorical perspective. J Neurochem 111: 291-314, 2009.

79. Pournaras CJ, Rungger-Brändle E, Riva CE, Hardarson SH and Stefansson E: Regulation of retinal blood flow in health and disease. Prog Retin Eye Res 27: 284-330, 2008.

80. Iadecola $\mathrm{C}$ and Nedergaard M: Glial regulation of the cerebral microvasculature. Nat Neurosci 10: 1369-1376, 2007.

81. Cioffi GA and Sullivan P: The effect of chronic ischemia on the primate optic nerve. Eur J Ophthalmol 9 (Suppl 1): S34-S36, 1999.

82. Harris A, Siesky B and Wirostko B: Cerebral blood flow in glaucoma patients. J Glaucoma 22 (Suppl 5): S46-S48, 2013.

83. Mozaffarieh M, Grieshaber MC and Flammer J: Oxygen and blood flow: Players in the pathogenesis of glaucoma. Mol Vis 14: 224-233, 2008

84. Bunting H, Still R, Williams DR, Gravenor M and Austin MW: Evaluation of plasma glutamate levels in normal tension glaucoma. Ophthalmic Res 43: 197-200, 2010.

85. Chrysostomou V, Rezania F, Trounce IA and Crowston JG: Oxidative stress and mitochondrial dysfunction in glaucoma. Curr Opin Pharmacol 13: 12-15, 2013.

86. Mozaffarieh M, Schoetzau A, Sauter M, Grieshaber M, Orgül S, Golubnitschaja $\mathrm{O}$ and Flammer J: Comet assay analysis of single-stranded DNA breaks in circulating leukocytes of glaucoma patients. Mol Vis 14: 1584-1588, 2008.

87. Tezel G and Wax MB: Hypoxia-inducible factor lalpha in the glaucomatous retina and optic nerve head. Arch Ophthalmol 122: 1348-1356, 2004

88. McElnea EM, Quill B, Docherty NG, Irnaten M, Siah WF, Clark AF, O'Brien CJ and Wallace DM: Oxidative stress, mitochondrial dysfunction and calcium overload in human lamina cribrosa cells from glaucoma donors. Mol Vis 17: 1182-1191, 2011.

89. Yuan L and Neufeld AH: Activated microglia in the human glaucomatous optic nerve head. J Neurosci Res 64: 523-532, 2001.

90. Tezel G and Wax MB: The immune system and glaucoma. Curr Opin Ophthalmol 15: 80-84, 2004.

91. Prasanna G, Krishnamoorthy R and Yorio T: Endothelin, astrocytes and glaucoma. Exp Eye Res 93: 170-177, 2011.

92. Harada T, Harada C, Nakamura K, Quah HM, Okumura A, Namekata K, Saeki T, Aihara M, Yoshida H, Mitani A, et al: The potential role of glutamate transporters in the pathogenesis of normal tension glaucoma. J Clin Invest 117: 1763-1770, 2007.

93. Munemasa Y and Kitaoka Y: Molecular mechanisms of retinal ganglion cell degeneration in glaucoma and future prospects for cell body and axonal protection. Front Cell Neurosci 6: 60, 2013.

94. Lebrun-Julien F, Duplan L, Pernet V, Osswald I, Sapieha P, Bourgeois P, Dickson K, Bowie D, Barker PA and Di Polo A: Excitotoxic death of retinal neurons in vivo occurs via a non-cell-autonomous mechanism. J Neurosci 29: 5536-5545, 2009.

95. Oku H, Fukuhara M, Komori A, Okuno T, Sugiyama T and Ikeda T: Endothelin-1 (ET-1) causes death of retinal neurons through activation of nitric oxide synthase (NOS) and production of superoxide anion. Exp Eye Res 86: 118-130, 2008. 
96. Golubnitschaja O, Yeghiazaryan K, Liu R, Mönkemann $\mathrm{H}$ Leppert D, Schild H, Haefliger IO and Flammer J: Increased expression of matrix metalloproteinases in mononuclear blood cells of normal-tension glaucoma patients. J Glaucoma 13: 66-72, 2004

97. Grieshaber MC and Flammer J: Does the blood-brain barrier play a role in Glaucoma? Surv Ophthalmol 52 (Suppl 2): S115-S121, 2007.

98. Hofman P, Hoyng P, vanderWerf F, Vrensen GF and Schlingemann RO: Lack of blood-brain barrier properties in microvessels of the prelaminar optic nerve head. Invest Ophthalmol Vis Sci 42: 895-901, 2001.

99. Grieshaber MC, Terhorst T and Flammer J: The pathogenesis of optic disc splinter haemorrhages: A new hypothesis. Acta Ophthalmol Scand 84: 62-68, 2006.

100.Farrall AJ and Wardlaw JM: Blood-brain barrier: Ageing and microvascular disease - systematic review and meta-analysis. Neurobiol Aging 30: 337-352, 2009.

101.Tong L, Balazs R, Soiampornkul R, Thangnipon W and Cotman CW: Interleukin-1 beta impairs brain derived neurotrophic factor-induced signal transduction. Neurobiol Aging 29: 1380-1393, 2008.

102. Allingham RR, Liu Y and Rhee DJ: The genetics of primary open-angle glaucoma: A review. Exp Eye Res 88: 837-844, 2009.

103. Weisschuh N, Neumann D, Wolf C, Wissinger B and Gramer E: Prevalence of myocilin and optineurin sequence variants in German normal tension glaucoma patients. Mol Vis 11: 284-287, 2005.

104. Weisschuh N, Wolf C, Wissinger B and Gramer E: Variations in the WDR36 gene in German patients with normal tension glaucoma. Mol Vis 13: 724-729, 2007.

105. Tang S, Toda Y, Kashiwagi K, Mabuchi F, Iijima H, Tsukahara S and Yamagata Z: The association between Japanese primary open-angle glaucoma and normal tension glaucoma patients and the optineurin gene. Hum Genet 113: 276-279, 2003.

106. Liu YH and Tian T: Hypothesis of optineurin as a new common risk factor in normal-tension glaucoma and Alzheimer's disease. Med Hypotheses 77: 591-592, 2011

107. Mi XS, Yuan TF and So KF: The current research status of normal tension glaucoma. Clin Interv Aging 9: 1563-1571, 2014

108. Guo Y, Chen X, Zhang H, Li N, Yang X, Cheng W and Zhao K: Association of OPA1 polymorphisms with NTG and HTG: A meta-analysis. PLoS One 7: e42387, 2012

109. Kawase K, Allingham RR, Meguro A, Mizuki N, Roos B, Solivan-Timpe FM, Robin AL, Ritch $\mathrm{R}$ and Fingert JH: Confirmation of TBK1 duplication in normal tension glaucoma. Exp Eye Res 96: 178-180, 2012.

110. Kim SH, Kim JY, Kim DM, Ko HS, Kim SY, Yoo T, Hwang SS and Park SS: Investigations on the association between norma tension glaucoma and single nucleotide polymorphisms of the endothelin-1 and endothelin receptor genes. Mol Vis 12 1016-1021, 2006.

111. Shibuya E, Meguro A, Ota M, Kashiwagi K, Mabuchi F, Iijima H, Kawase K, Yamamoto T, Nakamura M, Negi A, et al: Association of Toll-like receptor 4 gene polymorphisms with normal tension glaucoma. Invest Ophthalmol Vis Sci 49: 4453-4457, 2008

112. Fraenkl SA, Golubnitschaja O, Yeghiazaryan K, Orgül S and Flammer J: Differences in gene expression in lymphocytes of patients with high-tension, PEX, and normal-tension glaucoma and in healthy subjects. Eur J Ophthalmol 23: 841-849, 2013.

113. Jeoung JW, Seong MW, Park SS, Kim DM, Kim SH and Park KH: Mitochondrial DNA variant discovery in normal-tension glaucoma patients by next-generation sequencing. Invest Ophthalmol Vis Sci 55: 986-992, 2014.

114. Akiyama M, Yatsu K, Ota M, Katsuyama Y, Kashiwagi K, Mabuchi F, Iijima H, Kawase K, Yamamoto T, Nakamura M, et al: Microsatellite analysis of the GLC1B locus on chromosome 2 points to NCK 2 as a new candidate gene for normal tension glaucoma. Br J Ophthalmol 92: 1293-1296, 2008.

115. Murakami K, Meguro A, Ota M, Shiota T, Nomura N, Kashiwagi K, Mabuchi F, Iijima H, Kawase K, Yamamoto T, et al: Analysis of microsatellite polymorphisms within the GLC1F locus in Japanese patients with normal tension glaucoma. Mol Vis 16: 462-466, 2010.

116. Wolf C, Gramer E, Müller-Myhsok B, Pasutto F, Reinthal E, Wissinger B and Weisschuh N: Evaluation of nine candidate genes in patients with normal tension glaucoma: A case control study. BMC Med Genet 10: 91, 2009.
117. Writing Committee for the Normal Tension Glaucoma Genetic Study Group of Japan Glaucoma Society; Meguro A, Inoko H, Ota M, Mizuki N and Bahram S: Genome-wide association study of normal tension glaucoma: Common variants in SRBD1 and ELOVL5 contribute to disease susceptibility. Ophthalmology 117: 1331.e5-1338.e5, 2010.

118. Chi ZL, Akahori M, Obazawa M, Minami M, Noda T, Nakaya N, Tomarev S, Kawase K, Yamamoto T, Noda S, et al: Overexpression of optineurin E50K disrupts Rab8 interaction and leads to a progressive retinal degeneration in mice. Hum Mol Genet 19: 2606-2615, 2010

119. Chi ZL, Yasumoto F, Sergeev Y, Minami M, Obazawa M, Kimura I, Takada Y and Iwata T: Mutant WDR36 directly affects axon growth of retinal ganglion cells leading to progressive retinal degeneration in mice. Hum Mol Genet 19: 3806-3815, 2010.

120. Heiduschka P, Schnichels S, Fuhrmann N, Hofmeister S, Schraermeyer U,Wissinger B and Alavi MV:Electrophysiological and histologic assessment of retinal ganglion cell fate in a mouse model for OPA1-associated autosomal dominant optic atrophy. Invest Ophthalmol Vis Sci 51: 1424-1431, 2010.

121. Mi XS, Zhang X, Feng Q, Lo AC, Chung SK and So KF: Progressive retinal degeneration in transgenic mice with overexpression of endothelin-1 in vascular endothelial cells. Invest Ophthalmol Vis Sci 53: 4842-4851, 2012.

122. Gasparini L, Crowther RA, Martin KR, Berg N, Coleman M, Goedert $M$ and Spillantini MG: Tau inclusions in retinal ganglion cells of human P301S tau transgenic mice: Effects on axonal viability. Neurobiol Aging 32: 419-433, 2011.

123. Ning A, Cui J, To E, Ashe KH and Matsubara J: Amyloid-beta deposits lead to retinal degeneration in a mouse model of Alzheimer disease. Invest Ophthalmol Vis Sci 49: 5136-5143, 2008.

124. Harada C, Namekata K, Guo X, Yoshida H, Mitamura Y, Matsumoto Y, Tanaka K, Ichijo H and Harada T: ASK1 deficiency attenuates neural cell death in GLAST-deficient mice, a model of normal tension glaucoma. Cell Death Differ 17: $1751-1759,2010$

125. Ayub H, Khan MI, Micheal S, Akhtar F, Ajmal M, Shafique S, Ali SH, den Hollander AI, Ahmed A and Qamar R: Association of eNOS and HSP70 gene polymorphisms with glaucoma in Pakistani cohorts. Mol Vis 16: 18-25, 2010.

126. Fernández-Martínez L, Letteboer S, Mardin CY, Weisschuh N, Gramer E, Weber BH, Rautenstrauss B, Ferreira PA, Kruse FE, Reis A, et al: Evidence for RPGRIP1 gene as risk factor for primary open angle glaucoma. Eur J Hum Genet 19: 445-451, 2011.

127. Fingert JH, Robin AL, Stone JL, Roos BR, Davis LK, Scheetz TE, Bennett SR, Wassink TH, Kwon YH, Alward WL, et al: Copy number variations on chromosome $12 \mathrm{q} 14$ in patients with normal tension glaucoma. Hum Mol Genet 20: 2482-2494, 2011.

128. Janssen SF, Gorgels TG, van der Spek PJ, Jansonius NM and Bergen AA: In silico analysis of the molecular machinery underlying aqueous humor production: Potential implications for glaucoma. J Clin Bioinforma 3: 21, 2013.

129. Kumar S, Malik MA, Goswami S, Sihota R and Kaur J Candidate genes involved in the susceptibility of primary open angle glaucoma. Gene 577: 119-131, 2016.

130. Lascaratos G, Garway-Heath DF, Willoughby CE, Chau KY and Schapira AH: Mitochondrial dysfunction in glaucoma: Understanding genetic influences. Mitochondrion 12: 202-212, 2012.

131. Mabuchi F, Sakurada Y, Kashiwagi K, Yamagata Z, Iijima H and Tsukahara S: Association between genetic variants associated with vertical cup-to-disc ratio and phenotypic features of primary open-angle glaucoma. Ophthalmology 119: 1819-1825, 2012.

132. Monemi S, Spaeth G, DaSilva A, Popinchalk S, Ilitchev E, Liebmann J, Ritch R, Héon E, Crick RP, Child A, et al: Identification of a novel adult-onset primary open-angle glaucoma (POAG) gene on 5q22.1. Hum Mol Genet 14: 725-733, 2005

133. Nowak A, Majsterek I, Przybyłowska-Sygut K, Pytel D, Szymanek K, Szaflik J and Szaflik JP: Analysis of the expression and polymorphism of APOE, HSP, BDNF, and GRIN2B genes associated with the neurodegeneration process in the pathogenesis of primary open angle glaucoma. Biomed Res Int 2015: 258281, 2015

134. Pasutto F, Keller KE, Weisschuh N, Sticht H, Samples JR, Yang YF, Zenkel M, Schlötzer-Schrehardt U, Mardin CY, Frezzotti P, et al: Variants in ASB10 are associated with open-angle glaucoma. Hum Mol Genet 21: 1336-1349, 2012. 
135. Rangachari K, Dhivya M,Eswari Pandaranayaka PJ, Prasanthi N, Sundaresan P, Krishnadas SR and Krishnaswamy S: Glaucoma database. Bioinformation 5: 398-399, 2011.

136. Rezaie T, Child A, Hitchings R, Brice G, Miller L, Coca-Prados M, Héon E, Krupin T, Ritch R, Kreutzer D, et al: Adult-onset primary open-angle glaucoma caused by mutations in optineurin. Science 295: 1077-1079, 2002.

137. Sahay P, Rao A, Padhy D, Sarangi S, Das G, Reddy MM and Modak R: Functional activity of matrix metalloproteinases 2 and 9 in tears of patients with glaucoma. Invest Ophthalmol Vis Sci 58: BIO106-BIO113, 2017.

138. Stoilova D, Child A, Trifan OC, Crick RP, Coakes RL and Sarfarazi M: Localization of a locus (GLC1B) for adult-onset primary open angle glaucoma to the 2 cen-q13 region. Genomics 36: 142-150, 1996.

139. Stone EM, Fingert JH, Alward WL, Nguyen TD, Polansky JR, Sunden SL, Nishimura D, Clark AF, Nystuen A, Nichols BE, et al: Identification of a gene that causes primary open angle glaucoma. Science 275: 668-670, 1997.
140. Wirtz MK, Samples JR, Rust K, Lie J, Nordling L, Schilling K, Acott TS and Kramer PL: GLC1F, a new primary open-angle glaucoma locus, maps to 7q35-q36. Arch Ophthalmol 117: 237-241, 1999

141. Woo SJ, Kim JY, Kim DM, Park SS, Ko HS and Yoo T: Investigation of the association between $677 \mathrm{C}>\mathrm{T}$ and $1298 \mathrm{~A}>\mathrm{C}$ 5,10-methylenetetra- hydrofolate reductase gene polymorphisms and normal-tension glaucoma. Eye (Lond) 23: 17-24, 2009.

142. Yu-Wai-Man P, Stewart JD, Hudson G, Andrews RM, Griffiths PG, Birch MK and Chinnery PF: OPA1 increases the risk of normal but not high tension glaucoma. J Med Genet 47: 120-125, 2010.

This work is licensed under a Creative Commons Attribution-NonCommercial-NoDerivatives 4.0 International (CC BY-NC-ND 4.0) License. 